\title{
Physical Health or Emotional Problems
}

National Cancer Institute

\section{Source}

National Cancer Institute. Physical Health or Emotional Problems. NCI Thesaurus. Code C110988.

The state of a person's physical and emotional well-being. 